\title{
High survivin expression as a risk factor in patients with anal carcinoma treated with concurrent chemoradiotherapy
}

\author{
Ingeborg Fraunholz ${ }^{*}$, Claus Rödel ${ }^{1}$, Luitpold Distel ${ }^{2}$, Marget Rave-Fränk ${ }^{3}$, Daniela Kohler ${ }^{1}$, \\ Stefan Falk ${ }^{4}$ and Franz Rödel ${ }^{1}$
}

\begin{abstract}
Purpose: To investigate the prognostic value of survivin expression in pretreatment specimens from patients with anal cancer treated with concurrent 5-FU and mitomycin C-based chemoradiation (CRT).

Material and methods: Immunohistochemical staining for survivin was performed in pretreatment biopsies of 62 patients with anal carcinoma. Survivin expression was correlated with clinical and histopathological characteristics as well as local failure free- (LFFS), distant metastases free- (DMFS), cancer specific- (CSS), and overall survival (OS).

Results: Survivin staining intensity was weak in 10\%, intermediate in $48 \%$ and intense in $42 \%$ of the patients. No association between survivin expression and clinicopathologic factors (tumor stage, age and HIV status) could be shown. In univariate analysis, the level of survivin staining was significantly correlated with DMFS (low survivin vs. high survivin: $94 \%$ vs. $74 \%, p=0.04)$. T-stage, $\mathrm{N}$-stage and the tumor grading were significantly associated with OS and CSS and with DMFS and LFFS, respectively. In multivariate analysis, survivin was confirmed as independent prognostic parameter for DMFS (RR, 0.04; $p=0.02)$ and for OS (RR, 0.27; $p=0.04)$.

Conclusion: Our results demonstrated that the level of pretreatment survivin is correlated with the clinical outcome in patients with anal carcinoma treated with concurrent CRT. Further studies are warranted to elucidate the complex role of survivin for the oncologic treatment and to exploit the protein as a therapeutic target in combined modality treatment of anal cancer.
\end{abstract}

Keywords: Survivin, Anal cancer, Molecular marker, Concurrent chemoradiotherapy

\section{Background}

Survivin, the smallest and structurally unique member of the inhibitor of apoptosis protein family (IAP) [1] plays a prominent role within tumor biology [2]. As a prime example of a nodal cancer protein, it is involved in the regulation of a multitude of cellular networks, including tumor cell proliferation, apoptosis and response to unfavorable environmental conditions [3]. While it is highly expressed during fetal development and is down regulated in most terminally differentiated normal tissues, the protein is found to be re-expressed in virtually every human malignancy examined so far $[4,5]$. In

\footnotetext{
* Correspondence: inge.fraunholz@kgu.de

'Department of Radiotherapy and Oncology, Johann Wolfgang GoetheUniversity, Theodor-Stern-Kai 7, 60590, Frankfurt am Main, Germany Full list of author information is available at the end of the article
}

line with that, survivin has been recognized as a suitable prognostic and predictive marker for tumor onset, enhanced proliferative index, more aggressive tumor behavior and strongly correlates with a higher likelihood of tumor recurrence and impaired disease free- and overall survival rates $[4,6]$. Moreover, a correlation of elevated survivin expression with increased risk of recurrences, lymph node metastases, and shorter survival was shown beside others, in non-small cell lung cancer (NSCLC), T1 bladder carcinoma [7], rectal adenocarcinoma [8] and locally advanced prostate cancer [9] treated with radiation therapy or chemoradiation. Due to its universal over-expression and unique biological properties, survivin further displays a validated molecular target for cancer drug development $[10,11]$. A variety of preclinical studies have demonstrated that targeting the

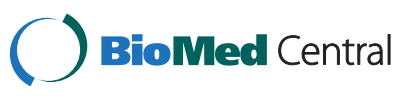


protein using RNA-interference, dominant negative mutants, antisense oligonucleotides and small molecule repressors sensitized tumor cells towards chemotherapy and irradiation and reduced tumor growth potential $[6,12]$. In addition, the translation of the preclinical findings into clinical practice is currently under way as a variety of survivin antagonists entered clinical phase I/II trials $[13,14]$.

In anal cancer, the prognostic value of apoptosis associated proteins has only been evaluated in a few studies on a restricted number of patients [15-19] showing that expression of Bcl-2, M30, p53, and nuclear factor $\mathrm{kB}$ $(\mathrm{NF}-\mathrm{kB})$ may be an independent predictor for disease free survival (DFS) and local control (LC), respectively. By contrast, a prognostic or predictive impact of survivin expression has not yet been investigated. Thus, the objective of the present study was to evaluate the expression of survivin in pretreatment biopsy specimen of patients with anal carcinoma treated with concurrent CRT and to correlate its immunoreactive score with clinicopathologic characteristics and clinical outcome.

\section{Patients and methods Patients}

62 patients, uniformly treated with definitive CRT for anal cancer in the Department of Radiotherapy and Oncology of the University Hospital of Frankfurt am Main and at the Department of Radiation Therapy of the University Hospital of Erlangen, who had available biopsy tissues and provided informed consent, were included in this study. Eligibility criteria were histological proof of anal canal carcinoma (squamous cell or basaloid or cloacogenic subtype) and curative intent of 5-FU and Mitomycin C-based CRT. Pretreatment evaluation consisted of physical and rectal-digital examination, proctoscopy with biopsy, CT/MRI of the abdomen and pelvis, chest $\mathrm{x}$-ray, serum chemistry, and complete blood count in all patients. Patients were staged according to the system adopted by the Union International Contre le Cancer (UICC) and the American Joint Committee on Cancer.

\section{Treatment modalities and follow-up}

3-D conformal radiation therapy was performed using either a 6- or 25-MV photon beam linear accelerator with individual field arrangement. The target volume included the primary tumor and the mesorectal, inguinal and internal iliac lymph nodes. The patients were treated with a median dose of 50.4 Gy (range, 41.4-60 Gy) with daily fractions of 1.8-2 Gy. A brachytherapy-boost with a median dose of 14 Gy (range, 12-22 Gy) was applied in 4 patients. 27 patients received an external boost to the primary tumor and/or enlarged lymph nodes of 5.4 Gy (range, 1.8-10.8 Gy). The anal boost volume was defined as anal gross tumor plus a safety margin of $2 \mathrm{~cm}$ in each direction. The dose specification was based on ICRU Report 50 recommendations. Concurrent chemotherapy consisted of two cycles of $5-\mathrm{FU}\left(1.000 \mathrm{mg} / \mathrm{m}^{2} /\right.$ 24 hours) as 4 or 5 -day continuous infusion in the first and fifth week of radiotherapy; mitomycin $\mathrm{C}$ was administered as intravenous bolus on day one of each cycle. During the treatment, patients were evaluated weekly to assess acute toxicity and compliance with the chemoradiation. Initial treatment response was assessed by rectal-digital examination and proctoscopy, with biopsies taken in case of suspicious residual tumor, 6-8 weeks after completion of CRT. The lymph node status was documented by pelvic CT/MRI-scan. Patients were scheduled for follow-up examinations, including history, physical and rectal-digital examination, and proctoscopy with biopsy in case of any suspicious finding, every 3 months for 2 years, followed every 6 months subsequently. Local control was defined as control of the anal primary tumor while nodal failure was considered as locoregional relapse. The median follow up time was 68 months (range 9-246).

\section{Immunohistochemical detection of survivin}

Immunohistochemical staining of survivin was performed on anal cancer biopsies by a horseradishperoxidase technique using a DAKO Autostainer plus (DAKO, Hamburg, Germany) according to the manufacturer's recommendation. For staining purpose, paraffin embedded tissue either mounted on microscope slides (Star Frost, Engelbrecht, Germany) or tissue microarrays as described in [20] were pretreated for 20 min with an Epitope Retrieval Solution (Dako). Next, slides were subjected to an automatic staining procedure with standardized $\mathrm{H}_{2} \mathrm{O}_{2}$ (10\%) treatment $(10 \mathrm{~min})$ and antibody (AF886, R\&D Systems, Wiesbaden, Germany) incubation (20 min, 1:750). Next, dextran polymer conjugated horseradish-peroxidase and 3,3'-diaminobenzidine (DAB) chromogen was used for visualization of the epitopeantibody reaction product and hematoxylin (37\%) for counterstaining. Negative control slides in the abcense of primary antibodies and positive controls with formalinfixed, paraffin-embedded cancer specimens of known survivin reactivity were included for each staining.

\section{Scoring of survivin expression}

Survivin immunoreactivity was analyzed considering both the percentage of positive cells and the intensity of staining. The staining intensity was scored as: $1+$ (weak), $2+$ (moderate) and 3+ (intense). The fraction of tumor cells with survivin positivity was assigned to: $1(0-25 \%)$, 2 (26-50\%), 3 (51-75\%) and 4 (> 75\%). To minimize interobserver variability, scoring was performed by two independent investigators without knowledge of the clinicopathological data. In discrepant cases, a final decision 
was made based on consensus by the investigators and, if necessary, a recount of the labeled cells was done. The percentage of positive tumor cells and the staining intensity were then multiplied to produce an individual labeling score for each case, ranging from 0 (no positive tumor cells) to 12 ( $>75 \%$ of tumor cells with intense staining). A weighted score $\leq 8$ was defined as "low" survivin expression and a weighted score of $>8$ as "high" survivin expression. This dichotomous variable served for correlation of survivin expression with clinicopathological parameters and survival.

\section{Statistical analysis}

Mean values are indicated with standard deviation. Differences between groups on continuous variables were tested using the Mann-Whitney test. Fisher's exact test was used to test differences between groups on categorical variables. Survival and time to recurrence were calculated from the date of CRT-beginning to the day of death and recurrences, respectively, or the date of the last follow-up. Disease free survival (DFS) was defined as the time between the start of CRT and tumor relapse (locoregional recurrence and/or distant metastases) or death due to nontumor related causes. Local failure free survival (LFFS) was defined as the time from the start of CRT to the first local tumor detection after CRT (i.e. non-complete response), local tumor recurrence after complete response or death from any cause. Survival curves were plotted according to the Kaplan-Meier method using SPSS 15.0 for Windows. Survival comparison between groups used the log-rank (Mantel-Cox) test.

The multivariate analysis was carried out with the Cox proportional hazard models.

\section{Results}

\section{Survivin immunostaining on pretreatment biopsies}

The intensity of survivin staining was usually homogeneous within a tumor specimen tested, but varied considerably among individual tumors. In Figure 1, representative examples of intense ( $>75$ positive tumor cells), intermediate $(25-75 \%)$ and weak $(\leq 25 \%)$ survivin immunoreactivity are illustrated. The distribution of the staining characteristics and labeling scores is presented in Table 1. As a dichotomous variable, survivin expression was defined as "low" (weighted score $\leq 8$ ) in 36 patients $(58 \%)$ and "high" (weighted score $>8$ ) in 26 patients (42\%). As shown in Table 2, no significant relationship was found for the dichotomized variable and clinicopathologic parameters such as T-stage, $\mathrm{N}$-stage, age and HIV status.

\section{Survivin and treatment response}

After CRT, a clinical complete response was diagnosed in 55 patients (low survivin vs. high survivin: $89 \%$ vs. $88 \%, p=1.0)$. Within these patients, a local recurrence occurred in 6 patients ( $16 \%$ vs. $4 \%, p=0.38)$. Local control was achieved in 49 patients $(75 \%$ vs. $86 \%, p=0.53)$. Distant metastases were evident in 8 patients $(6 \%$ vs. $23 \%, p=0.05)$. Within the 15 patients who have died (19\% vs. $31 \%, p=0.37), 9$ patients died from anal cancer ( $12 \%$ vs. $26 \%, p=0.47)$, two patients died from intercurrent disease and 4 patients from unknown causes.

As displayed in Figure 2, patients with low survivin expression had a significantly superior DMFS (94\% vs. $74 \%, p=0.04)$. OS was also superior, but without significance $(92 \%$ vs. $75 \%, p=0.09)$. In univariate analysis, the T-stage, $\mathrm{N}$-stage and the tumor grading were also significantly associated with OS and CSS and with DMFS and LFFS, respectively (Table 3). Factors significantly influencing the clinical endpoints such as survivin expression, T-stage, $\mathrm{N}$-stage and tumor grading as well as patients' gender were included in multivariate analysis. In the Cox models, survivin was confirmed as an independent prognostic parameter for DMFS (RR, $0.04 ; p=0.02)$ and for OS (RR, $0.27 ; p=0.04)$. As depicted in Table 4, Tstage was also an independent prognostic factors for DMFS (RR, $1.88 ; p=0.02)$.

\section{Discussion}

Despite respectable treatment response in nonmetastatic anal carcinoma with OS rates of $60-75 \%$, only a small amount of patients (10\%) with distant metastases will survive more than two years from the time of diagnosis [21]. Although clinical and pathological factors like tumor size and extent and nodal involvement have been regarded to be of prognostic significance, biomarkers have not yet been consistently be proven to predict tumor response [22]. Whereas some studies reported on a prognostic value of TP53, p21 and cyclin A, other investigations did not [23]. Thus, extended insights into individual tumor characteristics and the development of novel molecular indicators are seriously needed.

Deregulation of apoptosis is a pathogenic factor of many human diseases, and the ability to circumvent or evade apoptotic cell death is a critical hallmark of tumor cells [24]. Since deregulation in cell death pathways, for example by an elevated expression of anti-apoptotic molecules, may result in resistance to conventional treatment regimens including chemo and radiation therapy, these markers may be a novel class of molecular predictors. In the present study, we investigated the predictive and prognostic relevance of the apoptosis inhibitor survivin in biopsies derived from patients with anal carcinoma treated with definitive CRT. By using histochemical evaluation and scoring we demonstrated that pretreatment survivin expression is correlated with the clinical outcome-namely DMFS. These findings are in line with a variety of studies showing that a high survivin expression is correlated with increased risk of tumor 

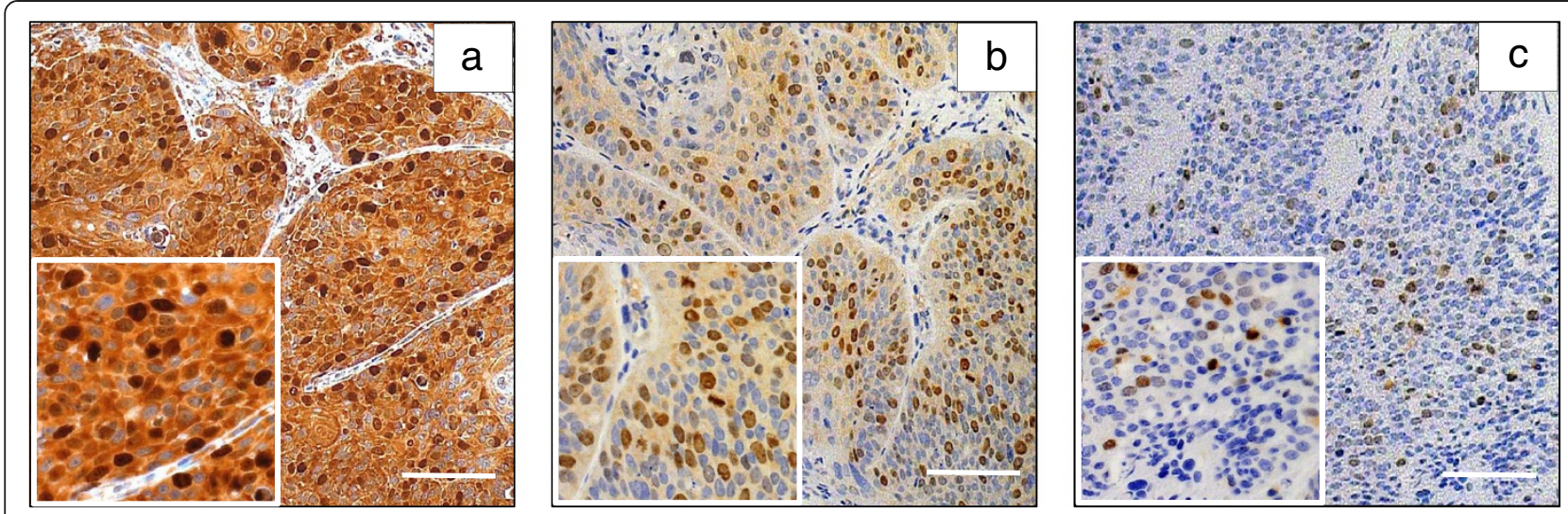

Figure 1 Examples of anal cancer biopsies with intense (a), intermediate (b) and weak (c) immunohistochemical staining of survivin in both, cytoplasm and nucleus of tumor cells. Original magnification x $100(a, b, c)$ and $\times 400$ (inserts), scale bar: $100 \mu \mathrm{m}$.

recurrences, lymph node metastases and lower survival after definitive radiotherapy or chemoradiation in esophageal [25], cervical [26], lung [27], early (T1/T2) prostate [9], and in nasal/paranasal sinus cancer [28]. More recent data further indicate that intratumoral survivin expression significantly decreased during neoadjuvant chemoradiation in esophageal and rectal cancer $[29,30]$. A failure in radiation provoked down-regulation, by contrast, was significantly associated with shortened overall survival and an increased likelihood to develop distant metastases. These results support the concept that measuring survivin expression may be suitable to predict individual metastatic behavior. To strengthen this hypothesis, an intermolecular cooperation between survivin and its family partner X-linked IAP (XIAP) has

Table 1 Results of immunohistochemistry

\begin{tabular}{lc}
\hline & $\begin{array}{c}\text { Patients } \\
\mathbf{n}(\%)\end{array}$ \\
\hline Percentage of immunopositive cells: & $1(2)$ \\
\hline $0-25 \%$ & $6(10)$ \\
\hline $26-50 \%$ & $10(16)$ \\
\hline $51-75 \%$ & $45(72)$ \\
\hline $76-100 \%$ & $6(10)$ \\
\hline Staining intensity: & $30(48)$ \\
\hline $1+$ & $26(42)$ \\
\hline $2+$ & $6(10)$ \\
\hline $3+$ & $30(48)$ \\
\hline Individual labeling score: & $26(42)$ \\
\hline $1-3$ & \\
\hline $4-8$ & $36(58)$ \\
\hline $9-12$ & $26(42)$ \\
\hline Dichotomized labeling score:
\end{tabular}

recently been reported to stimulate an invasive behavior and promote tumor cell metastases. Thus, both proteins are considered to modulate metastasis progression, possibly orchestrating a cellular network of transcription factor NF- $\mathrm{kB}$ dependent expression of fibronectin, $\beta-$ integrin signaling and activation of the cell motility kinases focal adhesion molecule (FAK) or matrix metalloproteinases $[31,32]$.

Table 2 Patients characteristics

\begin{tabular}{|c|c|c|c|c|}
\hline & No. of & low survivin* & high survivin** & p-value \\
\hline & & n (\%) & n (\%) & \\
\hline \multicolumn{5}{|l|}{ Age } \\
\hline$\leq 56$ years & 31 & $19(53)$ & $12(46)$ & 0.79 \\
\hline$>56$ years & 31 & $17(47)$ & $14(54)$ & \\
\hline \multicolumn{5}{|l|}{ Sex } \\
\hline Male & 26 & $15(42)$ & $11(42)$ & 1.0 \\
\hline Female & 36 & $21(58)$ & $15(58)$ & \\
\hline \multicolumn{5}{|l|}{ HIV-status } \\
\hline Positive & 15 & $7(19)$ & $8(31)$ & 0.37 \\
\hline Negative & 47 & $29(81)$ & $18(69)$ & \\
\hline \multicolumn{5}{|l|}{ T-stage } \\
\hline $\mathrm{T} 1 / 2$ & 44 & $26(72)$ & $18(62)$ & 0.78 \\
\hline $\mathrm{T} 3 / 4$ & 17 & $9(25)$ & $8(31)$ & \\
\hline Tx & 1 & $1(3)$ & $0(0)$ & \\
\hline \multicolumn{5}{|l|}{ N-stage } \\
\hline NO & 37 & $18(50)$ & $19(73)$ & 0.18 \\
\hline $\mathrm{N}+$ & 23 & $16(44)$ & $7(27)$ & \\
\hline $\mathrm{Nx}$ & 2 & $2(6)$ & $0(0)$ & \\
\hline \multicolumn{5}{|l|}{ Grading } \\
\hline $\mathrm{G} 1 / 2$ & 47 & $27(75)$ & $20(77)$ & 0.75 \\
\hline G3 & 12 & $6(17)$ & $6(23)$ & \\
\hline Gx & 3 & $3(8)$ & $(0)$ & \\
\hline
\end{tabular}

Abbreviations: HIV = human immunodeficiency virus.

${ }^{*}$ survivin - weighted score $\leq 8 ;{ }^{* *}$ survivin - weighted score $>8$. 

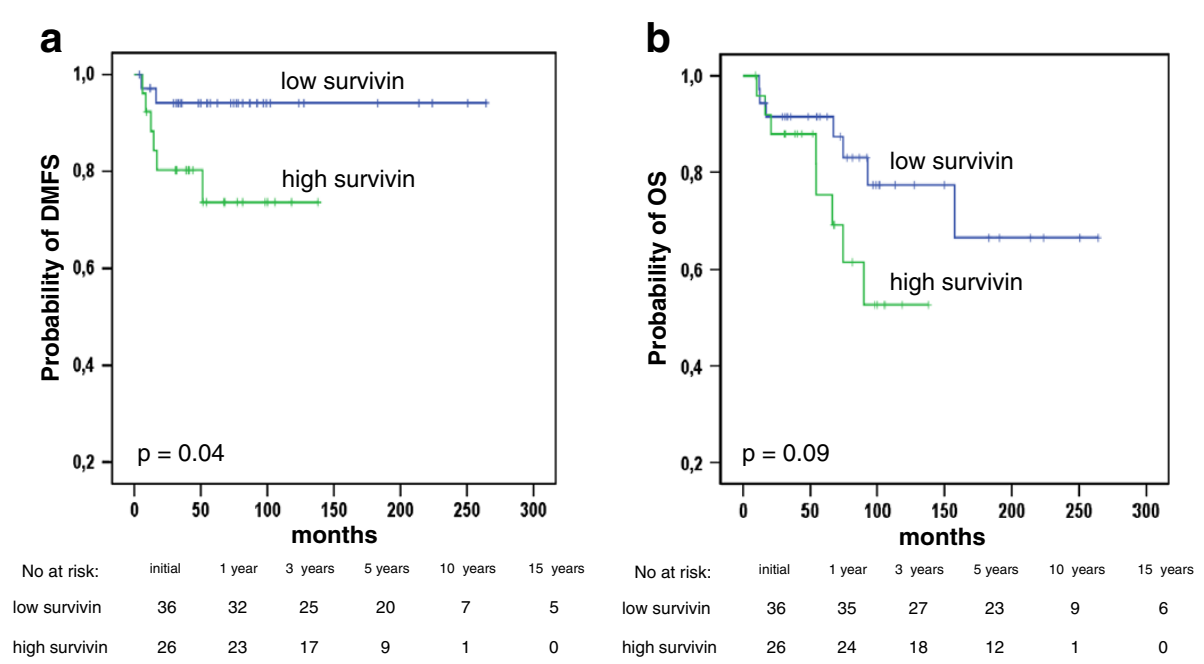

Figure 2 Distant metastases free survival (DMFS) (a) and Overall survival (OS) (b) according to pretreatment survivin expression (low survivin: weighted score $\leq \mathbf{8}$; high survivin: weighted score $>8$ ).

Due to its differential expression in cancerous and normal tissue and its requirement for regulating apoptosis, maintaining cancer cell viability and to modulate therapy response, survivin is supposed to be a suitable target for a molecular tumor therapy $[10,11]$. Indeed a variety of preclinical studies have convincingly demonstrated that survivin is a radiation resistance factor [33-35]. Moreover, attenuation of the protein by antisense oligonucleotides (ASO), small interfering RNAs (siRNAs), small molecule transcriptional inhibitors and

Table 3 Univariate analysis for prognostic factors influencing 5 year-survival

\begin{tabular}{llllllll}
\hline OS & p-value & $\frac{\text { CSS }}{(\%)}$ & $p$-value & $\frac{\text { DMFS }}{(\%)}$ & $p$-value & $\frac{\text { LFFS }}{(\%)}$ & -value \\
\hline
\end{tabular}

\begin{tabular}{|c|c|c|c|c|c|c|c|c|}
\hline Age & & & & & & & & \\
\hline$\leq 56$ years & 84 & 0.17 & 84 & 0.75 & 83 & 0.47 & 81 & 0.46 \\
\hline$>56$ years & 87 & & 92 & & 88 & & 82 & \\
\hline \multicolumn{9}{|l|}{ Sex } \\
\hline Male & 75 & 0.41 & 80 & 0.30 & 80 & 0.20 & 72 & 0.08 \\
\hline Female & 93 & & 93 & & 89 & & 89 & \\
\hline \multicolumn{9}{|l|}{ HIV-status } \\
\hline Positive & 73 & 0.27 & 73 & 0.07 & 72 & 0.08 & 73 & 0.13 \\
\hline Negative & 90 & & 93 & & 90 & & 84 & \\
\hline \multicolumn{9}{|l|}{ T-stage } \\
\hline $\mathrm{T} 1 / 2$ & 93 & 0.01 & 93 & $<0.01$ & 90 & 0.02 & 88 & 0.02 \\
\hline $\mathrm{T} 3 / 4$ & 67 & & 76 & & 72 & & 64 & \\
\hline \multicolumn{9}{|l|}{ N-stage } \\
\hline No & 93 & $<0.01$ & 93 & $<0.01$ & 90 & 0.19 & 100 & $<0.01$ \\
\hline $\mathrm{N}+$ & 73 & & 78 & & 81 & & 55 & \\
\hline \multicolumn{9}{|l|}{ Grading } \\
\hline $\mathrm{G} 1 / 2$ & 91 & $<0.01$ & 94 & 0.04 & 91 & 0.08 & 84 & 0.14 \\
\hline G3 & 64 & & 64 & & 65 & & 75 & \\
\hline \multicolumn{9}{|l|}{ Survivin } \\
\hline low* & 92 & 0.09 & 92 & 0.29 & 94 & 0.04 & 80 & 0.56 \\
\hline high** & 75 & & 82 & & 74 & & 85 & \\
\hline
\end{tabular}

Abbreviations: OS = overall survival; $C S S=$ cancer specific survival; DMFS = distant metastases-free survival; LFFS = local failure-free survival; HIV = human immunodeficiency virus. *Survivin - weighted score $\leq 8$; ${ }^{* *}$ survivin - weighted score $>8$. 
Table 4 Multivariate analysis for distant metastases-free survival (DMFS) and overall survival (OS)

\begin{tabular}{|c|c|c|c|c|c|c|}
\hline & \multirow[b]{2}{*}{ RR } & \multicolumn{2}{|l|}{ DMFS } & \multirow[b]{2}{*}{ RR } & \multicolumn{2}{|l|}{ os } \\
\hline & & $95 \% \mathrm{Cl}$ & p-value & & $95 \% \mathrm{Cl}$ & $p$-value \\
\hline \multicolumn{7}{|l|}{ Sex } \\
\hline Male/female & 1.33 & $0.14-12.94$ & 0.81 & 1.07 & $0.27-4.21$ & 0.92 \\
\hline \multicolumn{7}{|l|}{ HIV-status } \\
\hline Positive/negative & 0.24 & $0.03-2.08$ & 0.20 & 0.43 & $0.09-2.00$ & 0.28 \\
\hline \multicolumn{7}{|l|}{ T-stage } \\
\hline T1-2/T3-4 & 1.88 & $1.10-3.21$ & 0.02 & 1.31 & $0.96-1.80$ & 0.08 \\
\hline \multicolumn{7}{|l|}{$\mathrm{N}$-stage } \\
\hline $\mathrm{N} 0 / \mathrm{N}+$ & 1.35 & $0.89-2.03$ & 0.15 & 1.18 & $0.95-1.48$ & 0.14 \\
\hline \multicolumn{7}{|l|}{ Grading } \\
\hline G1-2/G3 & 1.62 & $0.91-2.89$ & 0.10 & 1.15 & $0.79-1.67$ & 0.47 \\
\hline \multicolumn{7}{|l|}{ Survivin } \\
\hline Low*/high** $^{*}$ & 0.04 & $0.003-0.59$ & 0.02 & 0.27 & $0.08-0.92$ & 0.04 \\
\hline
\end{tabular}

peptidomimetics impacted on apoptosis or clonogenic survival, radiosensitized glioblastoma [33], colorectal carcinoma [36], non-small cell lung cancer cells [37], and reduced tumor growth in xenograft models [6,12]. The translation of these preclinical findings to the clinical practice is currently under way with a number of phase I/II trials targeting survivin by the use of ASO (LY2181308) and small molecule inhibitors (YM155) in progress $[13,14]$. However, first results indicate modest activity as single agents $[38,39]$, but it is anticipated that when given combined with conventional chemotherapeutic drugs or irradiation these agents may exhibit enhanced individual success. Thus it is tempting to speculate, that combined anti survivin and CRT therapy in anal carcinoma will emerge as a novel treatment option in patients overexpressing the protein.

To the best of our knowledge, this is the first report evaluating survivin expression in anal carcinoma undergoing definitive CRT based on a well documented patient cohort and tumor material available. Although our investigation has some limitations due to restricted number of patients, low statistical power, and potential cut-point bias we consider the results as representative for a larger group of patients. Nevertheless, a prospective validation of the impact of survivin expression in anal carcinoma has to be performed on the basis of a clinical trial including a standardized protocol of immunohistochemical evaluation of the protein in pretreatment specimens.

In conclusion, we have shown that a histochemical evaluation of survivin expression in pretreatment biopsies of patients with anal carcinoma provides an easy accessible molecular indicator to identify patients at risk of distant metastatic disease. Based on these results, patients with high baseline survivin levels might benefit from intensified chemotherapeutic regimes and may be selected for additional molecular targeted strategies in future clinical trials.

\section{Competing interests}

The authors declare that they have no competing interests.

\section{Authors' contributions}

IF designed the study, supervised the analysis and prepared the manuscript. CR participated in the design and coordination of the study and revised the manuscript critically. LD provided tumor material and clinical follow up of patients and was involved in the preparation of the manuscript. DK carried out the immunohistochemical analysis and was involved in acquisition of data. MRF participated in the design of the study and was involved in the preparation of the manuscript. SF was involved in immunohistochemical studies and participated in the design and coordination of the study. FR supervised the analysis, was involved in histochemical analysis and contributed substantially in preparing the manuscript. All authors read and approved the final manuscript.

\section{Acknowledgements}

This work was supported by a grant of the German Federal Ministry of Education and Research (BMBF; m4 Cluster, 01EX1021). The authors gratefully acknowledge the excellent technical assistance of Mrs Gül Caylar and Mrs Petra Dinse, Pathology Associates, Frankfurt/Main.

\section{Author details}

${ }^{1}$ Department of Radiotherapy and Oncology, Johann Wolfgang GoetheUniversity, Theodor-Stern-Kai 7, 60590, Frankfurt am Main, Germany. ${ }^{2}$ Department of Radiation Oncology, Friedrich-Alexander-University, Universitäts-straße 27, 91054, Erlangen, Germany. ${ }^{3}$ Department of Radiation Oncology, Johann August-University, Robert-Koch-Straße 40, 37075 , Göttingen, Germany. ${ }^{4}$ Pathology Associates, Ginnheimer Landstraße 94, 60483, Frankfurt/Main, Germany.

Received: 17 February 2012 Accepted: 14 June 2012

Published: 14 June 2012

\section{References}

1. Ambrosini G, Adida C, Altieri DC: A novel anti-apoptosis gene, survivin, expressed in cancer and lymphoma. Nat Med 1997, 3:917-921.

2. Altieri DC: Survivin and IAP proteins in cell-death mechanisms. Biochem J 2010, 430:199-205.

3. Altieri DC: Survivin, cancer networks and pathway-directed drug discovery. Nat Rev Cancer 2008, 8:61-70.

4. Altieri DC: Validating survivin as a cancer therapeutic target. Nat Rev Cancer 2003, 3:46-54

5. Miura K, Fujibuchi W, Ishida K, Naitoh T, Ogawa H, Ando T, Yazaki N, Watanabe K, Haneda S, Shibata C, Sasaki I: Inhibitor of apoptosis protein family as diagnostic markers and therapeutic targets of colorectal cancer. Surg Today 2011, 41:175-182.

6. Mita AC, Mita MM, Nawrocki ST, Giles FJ: Survivin: key regulator of mitosis and apoptosis and novel target for cancer therapeutics. Clin Cancer Res 2008, 14:5000-5005.

7. Weiss C, von Römer F, Capalbo G, Ott OJ, Wittlinger M, Krause SF, Sauer R, Rödel C, Rödel F: Survivin expression as a predictive marker for local control in patients with high-risk T1 bladder cancer treated with transurethral resection and radiochemotherapy. Int J Radiat Oncol Biol Phys 2009, 74:1455-1460.

8. Rödel F, Hoffmann J, Grabenbauer GG, Papadopoulos T, Weiss C, Gunther K, Schick C, Sauer R, Rödel C: High survivin expression is associated with reduced apoptosis in rectal cancer and may predict disease-free survival after preoperative radiochemotherapy and surgical resection. Strahlenther Onkol 2002, 178:426-435.

9. Zhang M, Ho A, Hammond EH, Suzuki Y, Bermudez RS, Lee RJ, Pilepich M, Shipley WU, Sandler H, Khor LY, et al: Prognostic value of survivin in locally advanced prostate cancer: study based on RTOG 8610. Int J Radiat Oncol Biol Phys 2009, 73:1033-1042. 
10. Ryan BM, O'Donovan N, Duffy MJ: Survivin: a new target for anti-cancer therapy. Cancer Treat Rev 2009, 35:553-562.

11. Kanwar JR, Kamalapuram SK, Kanwar RK: Targeting survivin in cancer: the cell-signalling perspective. Drug Discov Today 2011, 16:485-494.

12. Rödel F, Reichert S, Sprenger T, Gaipl US, Mirsch J, Liersch T, Fulda S, Rödel C: The role of survivin for radiation oncology: moving beyond apoptosis inhibition. Curr Med Chem 2011, 18:191-199.

13. Tolcher AW, Mita A, Lewis LD, Garrett CR, Till E, Daud Al, Patnaik A, Papadopoulos K, Takimoto C, Bartels P, et al: Phase I and pharmacokinetic study of YM155, a small-molecule inhibitor of survivin. J Clin Oncol 2008, 26:5198-5203.

14. Talbot DC, Ranson M, Davies J, Lahn M, Callies S, Andre V, Kadam S, Burgess M, Slapak C, Olsen AL, et al: Tumor survivin is downregulated by the antisense oligonucleotide LY2181308: a proof-of-concept, first-in-human dose study. Clin Cancer Res 2010, 16:6150-6158.

15. Allal AS, Waelchli L, Brundler MA: Prognostic value of apoptosis-regulating protein expression in anal squamous cell carcinoma. Clin Cancer Res 2003, 9:6489-6496.

16. Ajani JA, Wang X, Izzo JG, Crane CH, Eng C, Skibber JM, Das P, Rashid A: Molecular biomarkers correlate with disease-free survival in patients with anal canal carcinoma treated with chemoradiation. Dig Dis Sci 2010, 55:1098-1105.

17. Allal AS, Brundler MA, Gervaz P: Differential expression of anti-apoptotic protein $\mathrm{BCl}-2$ in keratinizing versus non-keratinizing squamous cell carcinoma of the anus. Int J Colorectal Dis 2005, 20:161-164.

18. Allal AS, Alonso-Pentzke $L$, Remadi S: Apparent lack of prognostic value of MIB-1 index in anal carcinomas treated by radiotherapy. Br J Cancer 1998, 77:1333-1336.

19. Indinnimeo M, Cicchini C, Stazi A, Limiti MR, Ghini C, Mingazzini $P$ Vecchione A: Immunohistochemical assessment of Ki-67 as prognostic cellular proliferation marker in anal canal carcinoma. J Exp Clin Cancer Res 2000, 19:471-475.

20. Grabenbauer GG, Lahmer G, Distel L, Niedobitek G: Tumor-infiltrating cytotoxic $T$ cells but not regulatory $T$ cells predict outcome in anal squamous cell carcinoma. Clin Cancer Res 2006, 12:3355-3360.

21. Cummings BJ: Metastatic anal cancer: the search for cure. Onkologie 2006, 29:5-6.

22. Das P, Crane CH, Eng C, Ajani JA: Prognostic factors for squamous cell cancer of the anal canal. Gastrointest Cancer Res 2008, 2:10-14.

23. Lampejo T, Kavanagh D, Clark J, Goldin R, Osborn M, Ziprin P, Cleator S: Prognostic biomarkers in squamous cell carcinoma of the anus: a systematic review. Br J Cancer 2010, 103:1858-1869.

24. Hanahan D, Weinberg RA: Hallmarks of cancer: the next generation. Cell 2011, 144:646-674.

25. Zhu H, Wang Q, Hu C, Zhang W, Quan L, Liu M, Xu N, Xiao Z: High expression of survivin predicts poor prognosis in esophageal squamous cell carcinoma following radiotherapy. Tumour Biol 2011, 32:1147-1153.

26. Bache M, Holzapfel D, Kappler M, Holzhausen HJ, Taubert H, Dunst J, Hansgen G: Survivin protein expression and hypoxia in advanced cervical carcinoma of patients treated by radiotherapy. Gynecol Oncol 2007, 104:139-144.

27. Kren L, Brazdil J, Hermanova M, Goncharuk VN, Kallakury BV, Kaur P, Ross JS: Prognostic significance of anti-apoptosis proteins survivin and bcl-2 in non-small cell lung carcinomas: a clinicopathologic study of 102 cases. Appl Immunohistochem Mol Morphol 2004, 12:44-49.

28. Zhang Y, Huang D, Yu G: Survivin expression and its relationship with apoptosis and prognosis in nasal and paranasal sinus carcinomas. Acta Otolaryngol 2005, 125:1345-1350.

29. Vallbohmer D, Kuhn E, Warnecke-Eberz U, Brabender J, Hoffmann AC, Metzger R, Baldus SE, Drebber U, Hoelscher AH, Schneider PM: Failure in downregulation of intratumoral survivin expression following neoadjuvant chemoradiation in esophageal cancer. Pharmacogenomics 2008, 9:681-690.

30. Sprenger T, Rödel F, Beissbarth T, Conradi LC, Rothe H, Homayounfar K, Wolff HA, Ghadimi BM, Yildirim M, Becker H, et al: Failure of downregulation of survivin following neoadjuvant radiochemotherapy in rectal cancer is associated with distant metastases and shortened survival. Clin Cancer Res 2011, 17:1623-1631.

31. Mehrotra S, Languino LR, Raskett CM, Mercurio AM, Dohi T, Altieri DC: IAP regulation of metastasis. Cancer Cell 2010, 17:53-64.
32. Chu XY, Chen LB, Wang JH, Su QS, Yang JR, Lin Y, Xue LJ, Liu XB, Mo XB: Overexpression of survivin is correlated with increased invasion and metastasis of colorectal cancer. J Surg Oncol 2011

33. Chakravarti A, Zhai GG, Zhang M, Malhotra R, Latham DE, Delaney MA, Robe $P$, Nestler $U$, Song $Q$, Loeffler J: Survivin enhances radiation resistance in primary human glioblastoma cells via caspase-independent mechanisms. Oncogene 2004, 23:7494-7506.

34. Rödel C, Haas J, Groth A, Grabenbauer GG, Sauer R, Rödel F: Spontaneous and radiation-induced apoptosis in colorectal carcinoma cells with different intrinsic radiosensitivities: survivin as a radioresistance factor. Int J Radiat Oncol Biol Phys 2003, 55:1341-1347.

35. Asanuma K, Moriai R, Yajima T, Yagihashi A, Yamada M, Kobayashi D, Watanabe N: Survivin as a radioresistance factor in pancreatic cancer. Jpn J Cancer Res 2000, 91:1204-1209.

36. Rödel F, Hoffmann J, Distel L, Herrmann M, Noisternig T, Papadopoulos T, Sauer R, Rodel C: Survivin as a radioresistance factor, and prognostic and therapeutic target for radiotherapy in rectal cancer. Cancer Res 2005, 65:4881-4887

37. Iwasa T, Okamoto I, Suzuki M, Nakahara T, Yamanaka K, Hatashita E, Yamada Y, Fukuoka M, Ono K, Nakagawa K: Radiosensitizing effect of YM155, a novel small-molecule survivin suppressant, in non-small cell lung cancer cell lines. Clin Cancer Res 2008, 14:6496-6504.

38. Satoh T, Okamoto I, Miyazaki M, Morinaga R, Tsuya A, Hasegawa Y, Terashima M, Ueda S, Fukuoka M, Ariyoshi Y, et al: Phase I study of YM155, a novel survivin suppressant, in patients with advanced solid tumors. Clin Cancer Res 2009, 15:3872-3880.

39. Tanioka M, Nokihara H, Yamamoto N, Yamada Y, Yamada K, Goto Y, Fujimoto T, Sekiguchi R, Uenaka K, Callies S, Tamura T: Phase I study of LY2181308, an antisense oligonucleotide against survivin, in patients with advanced solid tumors. Cancer Chemother Pharmacol 2011, 68:505-511.

doi:10.1186/1748-717X-7-88

Cite this article as: Fraunholz et al:: High survivin expression as a risk factor in patients with anal carcinoma treated with concurrent chemoradiotherapy. Radiation Oncology 2012 7:88

\section{Submit your next manuscript to BioMed Central and take full advantage of:}

- Convenient online submission

- Thorough peer review

- No space constraints or color figure charges

- Immediate publication on acceptance

- Inclusion in PubMed, CAS, Scopus and Google Scholar

- Research which is freely available for redistribution 